Tohoku J. Exp. Med., 2006, 209, 361-367

Case Report

\title{
Small Cell Undifferentiated Carcinoma of the Ascending Colon with Rapid Enlargement after Resection: Report of a Case and Review of the Literature
}

\author{
Ouki Yasui, Fuminito Tsukamoto and Kazuhiro Kudo \\ Department of Surgery, Akita Roasi Hospital, Odate, Japan
}

\begin{abstract}
Yasui, O., Tsukamoto, F. and Kudo, K. Small Cell Undifferentiated Carcinoma of the Ascending Colon with Rapid Enlargement after Resection: Report of a Case and Review of the Literature. Tohoku J. Exp. Med., 2006, 209 (4), 361-367 — Although adenocarcinoma represents the vast majority of neoplasms of the large intestine, small cell undifferentiated carcinoma (SCUC) also arises from the colorectum. SCUC of the colorectum is highly malignant and shares the similarities in histologic characteristics, behavior, and histochemistry with SCUC of the lung. We report herein a case of SCUC in the ascending colon with rapid enlargement after resection. A 70-year-old male, who presented to a nearby physician with chief complaints of pain in the right lower quadrant, was referred to our hospital. We found a tumor mass that was approximately $15 \mathrm{~cm}$ in size in the right lower quadrant. Computed tomography (CT) images showed an irregularly shaped tumor, located inferior to the lower border of the right kidney and in the area of the ascending colon. By colonoscopy, we found a circumferential tumor of the ascending colon. A biopsy indicated it to be SCUC. The patient underwent right hemicolectomy. Two weeks after the resection, we palpated a tumor mass in the same area. The abdominal CT images showed a tumor mass that was approximately $10 \mathrm{~cm}$ in size. The tumor rapidly enlarged, and the patient died of multiple organ failure. SCUC is a tumor with a high malignant potential. Radical treatment cannot be achieved by surgical therapy alone and hence further studies of effective adjuvant therapy would be required. —— small cell undifferentiated carcinoma; SCUC; colon; chemotherapy
\end{abstract}

(C) 2006 Tohoku University Medical Press

Since Barnard (1926) reported on small cell undifferentiated carcinoma (SCUC) of the lungs, this disease has been known to have high malignancy and poor prognosis. The lung has been reported to be the primary origin in most cases of SCUC. However, it can develop in the gastrointestinal tract, breasts, prostate gland, and uterus. In this disease, a high degree of biological malig- nancy and advanced vascular invasion are observed. It has been reported that cases with lymph node or hematogenous metastasis at the time of carcinoma detection have poor prognoses (Orenstein and Schwarts 1987; Redman and Pazdur 1987). Treatment by surgical resection alone is insufficient, and multidisciplinary treatment including chemotherapy is necessary.

Received February 10, 2006; revision accepted for publication May 16, 2006. Japan.

Correspondence: Ouki Yasui, Akita Rosai hospital, 30 Shimotai, Karuizawa, Odate city, Akita 018-5604,

e-mail: ouki@sweet.ocn.ne.jp 
We report a case of SCUC in the ascending colon with rapid enlargement after cytoreductive surgery and the literature is reviewed with particular emphasis on the clinical characteristics, therapy, and outcome of patients with SCUC of the colorectum.

\section{Case Report}

A 70-year-old male became aware of pain in the right lower quadrant from early May 2004 and sought medical care from a nearby physician. At that time, the physician found a tumor in the right lower quadrant and the patient was diagnosed with an intraperitoneal tumor. The patient was then referred to our department on June 1, 2004. The patient experienced mild pain upon palpation in the right lower quadrant. An immovable, elastic, and firm tumor, which was approximately 15 $\mathrm{cm}$, was palpated in the right lower quadrant.

Laboratory data on admission were as follows: red blood cells were $261 \times 10^{4} / \mathrm{ml}$, hemoglobin $8.4 \mathrm{~g} / \mathrm{dl}$, and lactate dehydrogenase 275 IU/L. The tumor markers were carcinoembryonic antigen (CEA) $14.5 \mathrm{ng} / \mathrm{ml}$, neuron specific enolase (NSE) $25.9 \mathrm{ng} / \mathrm{ml}$, and sialyl Lewis x (SLX) $44.0 \mathrm{U} / \mathrm{ml}$, which were mildly elevated and carbohydrate antigen 19-9 (CA19-9) $1.0 \mathrm{U} / \mathrm{mL}$ and progastrin releasing peptide (PROGRP) $9.1 \mathrm{pg} / \mathrm{ml}$, which were within normal limits. Abdominal ultrasound examination showed a solid tumor in the light lower quadrant with various echo levels from high to low intensity. Abdominal computed tomography (CT) examination showed an abnormality, an irregularly shaped tumor, located inferior to the lower border of the right kidney and in the area of the ascending colon (Fig. 1). Abdominal magnetic resonance imaging (MRI) examination showed a tumor with low signal intensity on the T1 weighted images and high signal intensity on the T2 weighted images. Barium enema examination showed a $15-\mathrm{cm}$ tumor mass extending from the hepatocolic flexure to the cecum (Fig. 2). The tumor had irregular protrusions into the lumen. Colonoscopy examination revealed a white circumferential tumor with irregular protrusions into the lumen of the ascending colon. The tumor caused nearly complete intesti-

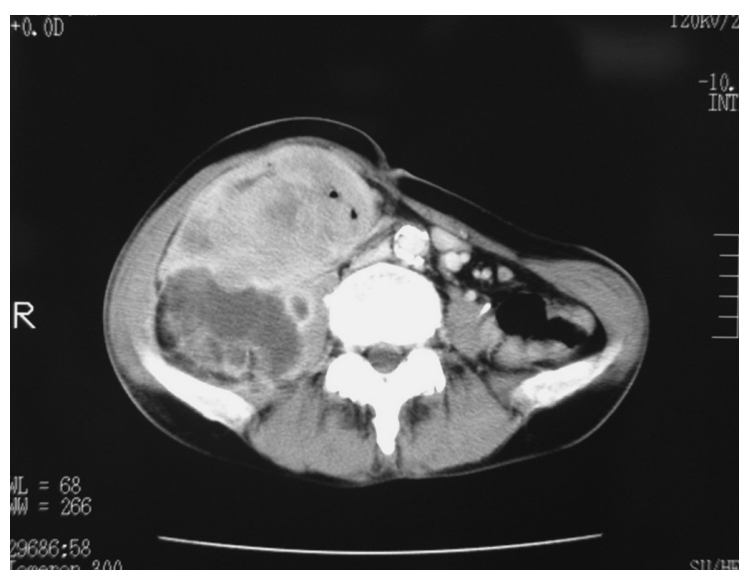

Fig. 1. Abdominal CT examination. A tumor was observed as a $15-\mathrm{cm}$ mass in the right abdominal area.

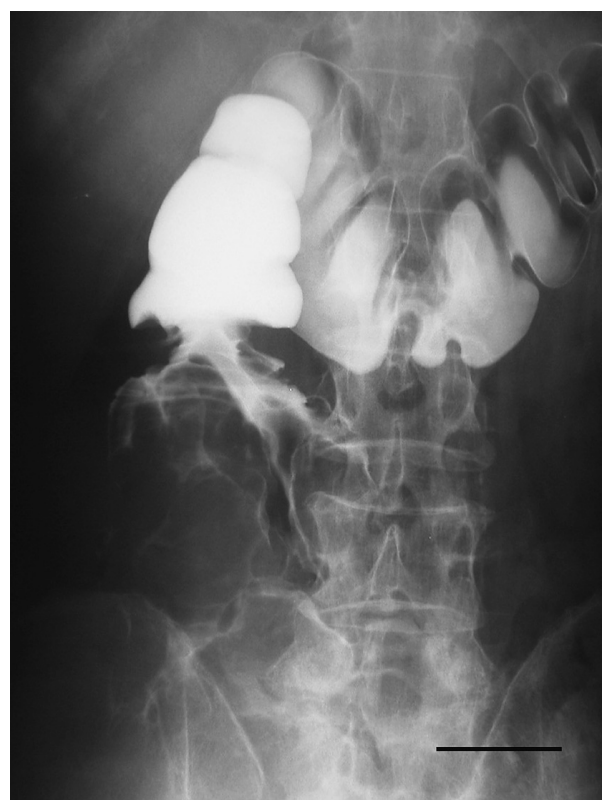

Fig. 2. Barium enema examination. A $15-\mathrm{cm}$ tumor mass was observed, extending from the hepatocolic flexure to the cecum. It had irregular protrusions into the lumen $(\mathrm{Bar}=5.0 \mathrm{~cm})$.

nal obstruction. It was diagnosed to be small cell carcinoma from the biopsy.

From the above findings, we made the diagnosis of small cell carcinoma of ascending colon origin and performed surgery on June 17, 2004. The tumor was white, elastic and firm and approximately $15 \mathrm{~cm}$ from perioperative laparo- 


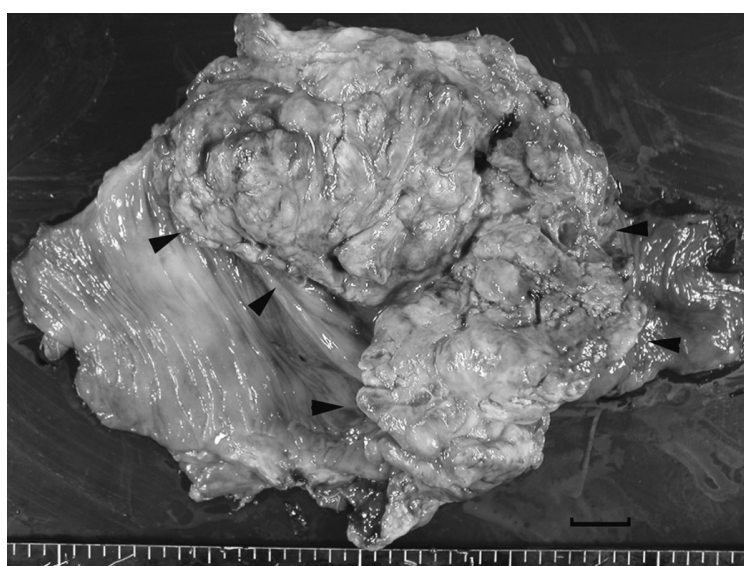

Fig. 3. Resected specimen. A tumor mass was observed in the ascending colon that was $15 \times$ $10 \mathrm{~cm}$ in size (arrow) (Bar $=20 \mathrm{~mm})$.

scopic findings. It had infiltrated dorsally between the psoas major muscles and iliacus muscles. Radical surgery was not performed to resect the tumor, because it would have likely caused an injury to the lumbar plexus. Therefore, we performed the resection leaving some residual tumor tissues. Peritoneal dissemination, lymph node metastasis, or liver metastasis was not observed.

Resected specimens showed that the tumor mass $(15 \mathrm{~cm} \times 10 \mathrm{~cm})$ was located in the ascending colon with irregular protrusions of the mucous membrane (Fig. 3). Pathological examination revealed that the tumor had infiltrated beyond the serosa, and advanced lymphatic vessel and venous invasions were observed. However, no metastasis to the lymph nodes was observed. The tumor cells were small with acidophilic cytoplasm and prominent nucleoli and coarse chromatin in an oval nucleus (Fig. 4). The tumor cells grew in a diffuse sheet-like arrangement. The tumor cells were positive for synaptophysin, CD56, and chromogranin A but negative for NSE. Secretory granules were observed by Grimelius staining. No components of adenoma or adenocarcinoma were found.

Postoperatively, the temperature of the patient remained consistently elevated above $38^{\circ} \mathrm{C}$. Two weeks after surgery, a recurrent tumor mass was palpated in the right lower quadrant.

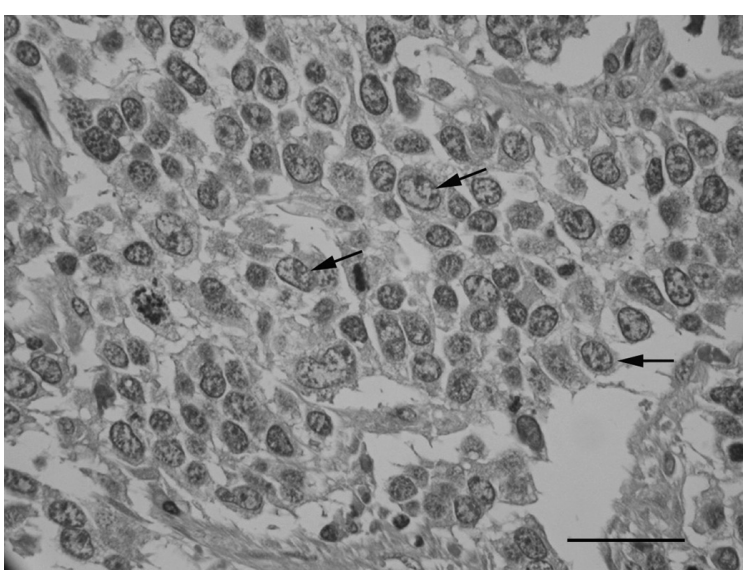

Fig. 4. The tumor cells grow in a diffuse sheet-like arrangement. They have spindle shape nucleus and scanty cytoplasm (arrows). $(\mathrm{H} \& \mathrm{E}$ stain, $\times 100$, Bar $=100 \mu \mathrm{m})$

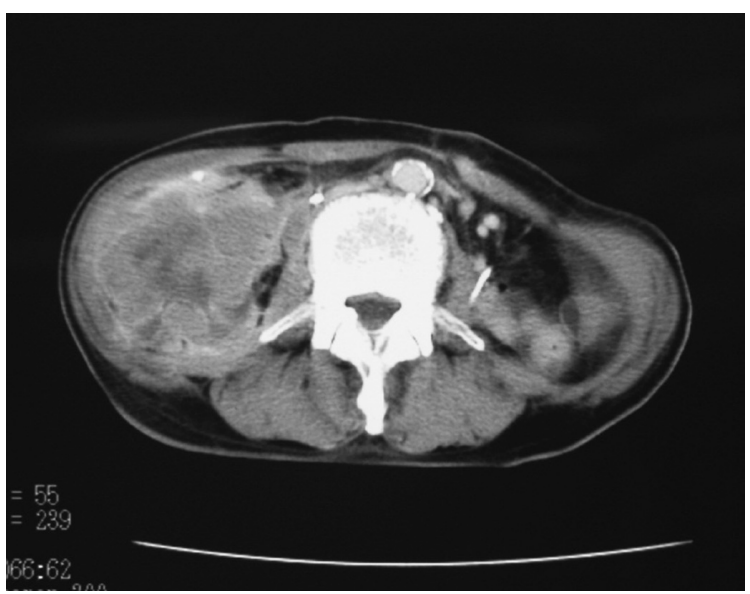

Fig. 5. Abdominal CT examination 14 days postoperation. A $10-\mathrm{cm}$ tumor mass was observed in the right abdominal area.

The formation of a $10-\mathrm{cm}$ tumor mass was observed in the abdominal CT images (Fig. 5). It was diagnosed as a local recurrence of the SCUC. The tumor rapidly enlarged and the patient died of multiple organ failure on July 22, 2004.

\section{Discussion}

The clinical course of the neoplastic disease in the present patient leaves no doubt that the tumor was highly malignant. Histologically, a cell of SCUC has a small round or spindle shape with a hematoxyphilic nucleus and scanty cyto- 
plasm. The size of the cell is up to three times that of a small lymphocyte. The cells have solid, alveolar, rosette-like, ribbon, cord-like, or streamlike growth patterns. Combined small cell carcinoma is a subtype and is a combination of small cell carcinoma with adenocarcinoma or squamous cell carcinoma. Carcinoid has low malignancy and good prognosis. The mitotic index is considered to be useful in distinguishing SCUC from carcinoid. SCUC produces peptide hormones such as adrenocorticotropic hormone, anti-diuretic hormone, gastrin releasing peptide and biologically active amines such as serotonin (Barnard 1926). The ultra-fine morphology of the tumor cell indicates the presence of neuroendocrine granules in the cell. It is also called "small cell neuroendocrine carcinoma."

Approximately $95 \%$ of SCUC cases are of bronchial origin. However, it can be derived from the uterine cervix, trachea, pharynx, thymus, prostate gland, and salivary gland, but it is reported to be rare from the digestive tract (Redman and Pazdur 1987; Remick et al. 1987). Remick et al. (1987) reported that the percentages of small cell carcinoma in the digestive tract are $0.2 \%$ for the colon, $0.1 \%$ for the stomach, and $0.05-2.4 \%$ for the esophagus. Dukes (1950) was the first to report on small cell carcinoma of the colon. Most of the reports on small cell carcinoma of the colon are case reports. Reports other than the large scale investigation by Gaffey et al. (1990) are based on only a small number of patients.

The summary of the reported cases of SCUC is shown in Table 1. We examined clinicopathologies, treatments, and outcomes in 38 patients. Their mean age was 57.6 years old, and the male to female ratio was 20:18. Small cell carcinoma was located in the cecum in 7 patients $(18.4 \%)$, ascending colon in 7 patients $(18.4 \%)$, transverse colon in 3 patients $(7.9 \%)$, sigmoid colon in 3 patients $(7.9 \%)$, rectum in 16 patients $(42.1 \%)$, and proctos in 2 patients $(5.3 \%)$. The majority of patients had small cell carcinoma in the rectum. Most patients had type 2, and the mean tumor size was $68.6 \mathrm{~mm}$. There were 24 patients $(63.2 \%)$ with lymph node metastases $(63.2 \%)$ and 15 patients $(39.5 \%)$ with liver metastases.
Chemotherapy is the first choice of treatment for small cell carcinoma of pulmonary origin. In contrast, the majority of the patients with SCUC of the colorectum underwent resection only. However, in recent years many reported cases have included chemotherapy as an adjuvant therapy. Chemotherapy was performed using cisplatin, etoposide, and 5-fluorouracil in many cases. The mean survival time (MST) was 85.1 weeks. The MSTs for patients who underwent resection only and for those who also underwent adjuvant chemotherapy were 67.0 weeks and 121.4 weeks, respectively, indicating a longer survival time with adjuvant chemotherapy.

Recently, longer survival has been observed in patients treated with the combination of cisplatin and irinotecan hydrochloride for the small cell carcinoma of the lung (Noda et al. 2002). Furthermore, Turrisi et al. (1999) reported the usefulness of cisplatin and etoposide in combination with radiation therapy, and the treatment results are anticipated to be good in the future. Eberhardt et al. (1999) have studied trimodality therapy for the small cell carcinoma of the lung, chemotherapy and radiation therapy followed by surgery, and reported excellent treatment results. Because the multidisciplinary treatment method has been reported to be useful, such a treatment method has also been considered necessary for advanced small cell carcinoma of the colon. A set protocol has not yet been established, and further studies are necessary.

For our case, there was an intestinal obstruction at the time of the preoperative examination. Therefore, cytoreductive surgery was performed to remove the intestinal obstruction, and adjuvant chemotherapy was planned. However, since high fever continued after the surgery, we could not perform the chemotherapy. The tumor enlarged rapidly, and the patient died before receiving adjuvant chemotherapy. Vilor et al. (1995) also made a similar report of a case in which they performed cytoreductive surgery. The risk appears to be high for rapid postoperative progression of advanced small cell carcinoma.

Since the report by Buinauskas et al. (1958), there have been many reports on the relationship 


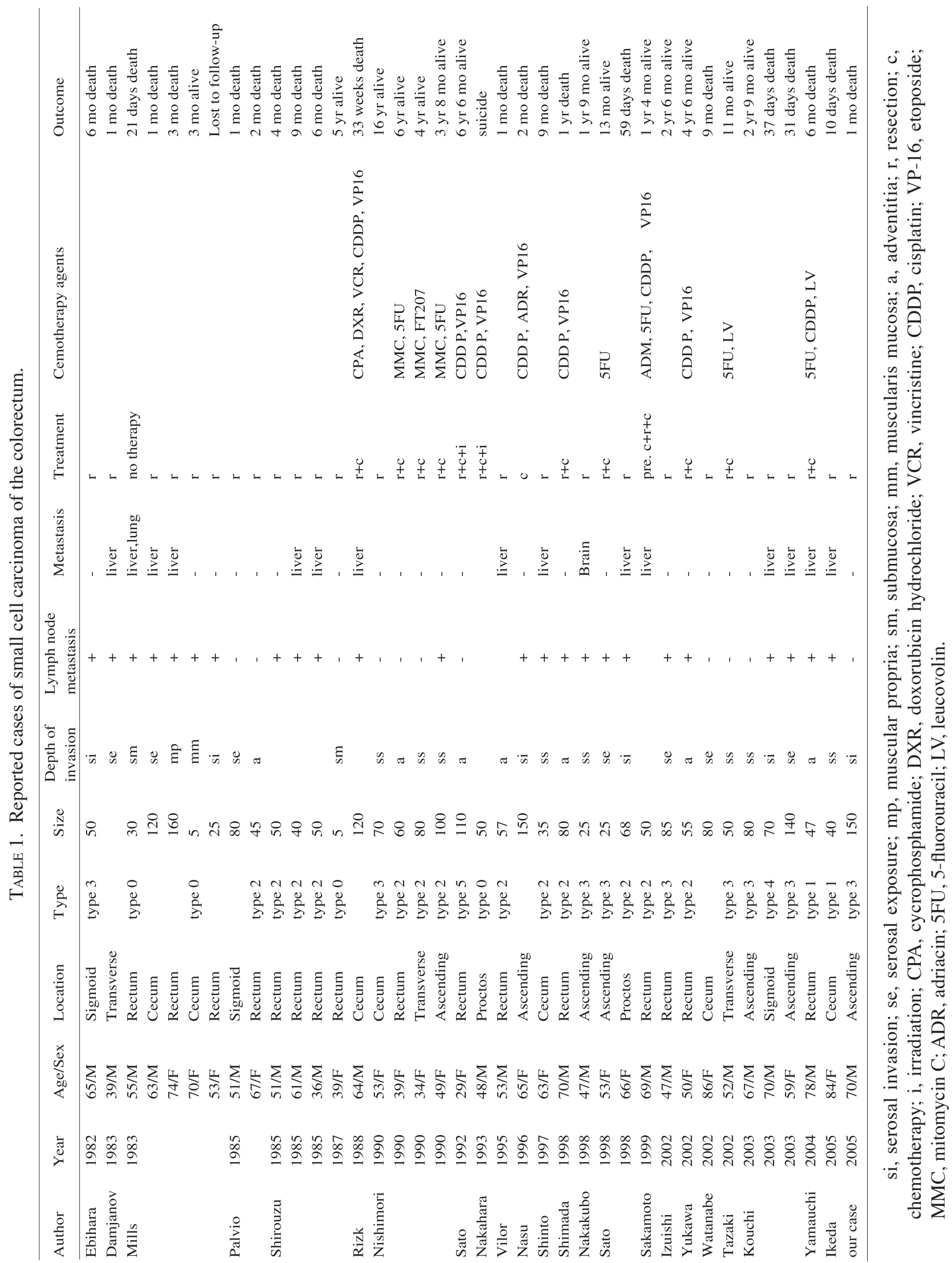


between cancer growth and surgical invasion. The mechanism is unknown, but it has been reported that various immune functions decline under surgical invasion, and cancer growth and metastasis are promoted (Riddle and Berenbaum 1967; Slade et al. 1975; McLoughlin et al. 1979; Lukomska et al. 1983; Hansbrough et al. 1984; Wang et al. 1980; Kodama et al. 1992). The decline in immune function and the growth potential of small cell carcinoma are closely related. There is an option of chemotherapy after cytoreductive surgery in a variety of gastroenterological cancers. However, in our patient, the surgical stress of excessive invasion by cytoreductive surgery was believed to have promoted metastasis and should have been avoided.

The resolution of internal obstruction is still considered the general rule for a case such as our patient with advanced tumor that causes obstruction, even for small cell carcinoma. In this patient, the possibility cannot be denied that an invasion by the tumor resection, cytoreductive surgery, could have hastened the unfavorable outcome. Although future studies are required, an intestinal obstruction should be resolved by a method which has low invasiveness such as gastrointestinal drainage and bypass surgery. Subsequently, a selection of such method as chemotherapy and radiation therapy would be useful.

\section{References}

Barnard, W.G. (1926) The nature of the "oat-celled sarcoma" of the mediastinum. J. Pathol. Bacteriol., 9, 241-244.

Buinauskas, P., McDonald, G.O. \& Cole, H. (1958) Role of operative stress on the resistance of the experimental animal to inoculated cancer cells. Ann. Surg., 148, 642-645.

Damjanov, I., Amenta, P.S. \& Bosman, F.T. (1983) Undifferentiated carcinoma of the colon containing exocrine, neuroendocrine and squamous cells. Virchows Arch. A Pathol. Anat. Histopathol., 401, 57-66.

Dukes, C.E. (1950) The surgical pathology of rectal caner. Am. J. Surg., 79, 66-71.

Eberhardt, W., Stamatis, G., Stuschke, M., Wilke, H., Muller, M.R., Kolks, S., Flasshove, M., Schutte, J., Stahl, M., Schlenger, L., Budach, V., Greschuchna, D., Stuben, G., Teschler, H., Sack, H. \& Seeber, S. (1999) Prognostically orientated multimodality treatment including surgery for selected patients of small-cell lung cancer patients stages IB to IIIB: long-term results of a phase II trial. $B r . J$. Cancer, 81, 1206-1212.

Ebihara, Y. (1982) Anaplastic small cell carcinoma of the sigmoid colon with peculiar histology: its histogenesis. $J$.
Med. Toho., 29, 287-293.

Gaffey, M.J., Mills, S.E. \& Lack, E.E. (1990) Neuroendocrine carcinoma of the colon and rectum. A clinicopathologic, ultrastructural, and immunohistochemical study of 24 cases. Am. J. Surg. Pathol., 14, 1010-1023.

Hansbrough, J.F., Bender, E.M., Zapata-Sirvent, R. \& Anderson, J. (1984) Altered helper and suppressor lymphocyte populations in surgical patients. A measure of postoperative immunosuppression. Am. J. Surg., 148, 303-307.

Ikeda, H., Tsuji, K., Saito, M. \& Hirakawa, E. (2005) A case of cecal endocrine cell carcinoma manifesting as ileus with poor prognosis. J. Jpn. Surg. Assoc., 66, 1670-1674.

Izuishi, K., Arai, T., Ochiai, A., Ono, M., Sugito, M., Tajiri, H. \& Saito, N. (2002) Long-term survival in advanced small cell carcinoma of the colorectum: report of a case. Surg. Today, 32, 72-74.

Kodama, M., Kodama, T., Nishi, Y. \& Totani, R. (1992) Does surgical stress cause tumor metastasis? Anticancer Res., 12, 1603-1616.

Kouchi, Y., Jimbou, M., Shigeta, M., Inokuchi, T., Fujita, Y., Miyahara, M., Kubo, H., Hasegawa, H. \& Miyashita, H. (2003) Neuroendocrine carcinoma of the colon: report of 3 cases. Jpn. J. Gastroenterol. Surg., 36, 503-508.

Lukomska, B., Olszewski, W.L., Engeset, A. \& Kolstad, P. (1983) The effect of surgery and chemotherapy on blood NK cell activity in patients with ovarian cancer. Cancer, 51, 465-469.

McLoughlin, G.A., Wu, A.V., Saporoschetz, I., Nimberg, R. \& Mannick, J.A. (1979) Correlation between anergy and a circulating immunosuppressive factor following major surgical trauma. Ann. Surg., 190, 297-304.

Mills, S.E., Allen, M.S., Jr. \& Cohen, A.R. (1983) Small-cell undifferentiated carcinoma of the colon. A clinicopathological study of five cases and their association with colonic adenomas. Am. J. Surg. Pathol., 7, 643-651.

Nakahara, H., Moriya, Y., Shinkai, T. \& Hirota, T. (1993) Small cell carcinoma of the anus in a human HIV carrier: report of a case. Surg. Today, 23, 85-88.

Nakakubo, Y., Inomata, H., Nishiyama, T., Kubota, H., Tanaka, H. \& Kato, H. (1998) A case of undifferentiated carcinoma of the asceding colon found out after removal of a brain metastasis. J. Jpn. Surg. Assoc., 59, 2633-2636.

Nasu, J., Kotake, K., Koyama, Y., Imura, J., Igarashi, S. \& Tsumuraya, M. (1996) Endocrine cell carcinoma of the colon: report of a case. J. Jpn. Soc. Coloproctol., 49, 161-166

Nishimori, T., Okuno, M., Ikehara, T., Nagayama, M., Togo, K., Kawaguchi, M., Kato, Y., Ohira, M. \& Umemiya, K. (1990) Undifferentiated carcinoma of the large intestine. A clinicopathological study. J. Jpn. Soc. Coloproctol., 43, 316-322.

Noda, K., Nishiwaki, Y., Kawahara, M., Negoro, S., Sugiura, T., Yokoyama, A., Fukuoka, M., Mori, K., Watanabe, K., Tamura, T., Yamamoto, S. \& Saijo, N. (2002) Irinotecan plus cisplatin compared with etoposide plus cisplatin for extensive small-cell lung cancer. N. Engl. J. Med., 346, 85-91.

Orenstein, J.M. \& Schwartz, A.M. (1987) Small-cell undifferentiated carcinoma of the colorectum. Ultrastruct. Pathol., 11, 781-786.

Palvio, D.H.B., S $\phi$ rensen, F.B. \& Kl $\phi$ ve-mogensen, M. (1985) Stem cell carcinoma of the colon and rectum. Report of two cases and review of the literature. Dis. Colon Rectum. 
28, 440-445.

Redman, B.G. \& Pazdur, R. (1987) Colonic small cell undifferentiated carcinoma: a distant pathological diagnosis with therapeutic implications. Am. J. Gastroenterol., 82, 382-385.

Remick, S.C., Hafez, G.R. \& Carbone, P.P. (1987) Extrapulmonary small-cell carcinoma. A review of the literature with emphasis on therapy and outcome. Medicine, 66, 457-471.

Riddle, P.R. \& Berenbaum, M.C. (1967) Postoperative depression of the lymphocyte response to phytohaemagglutinin. Lancet, 1, 746-748.

Rizk, S.L., Roseman, D.L., Bonomi, P., Sky-Peck, H., Clark, J., Lee, I. \& Gould, V.E. (1988) Elevated creatine phosphokinase MB in a patient with neuroendocrine carcinoma of the colon-evidence for a tumor marker. Report of a case. Dis. Colon Rectum., 31, 318-322.

Sakamoto, Y., Kitajima, Y., Ogawa, A., Hidaka, K. \& Miyazaki, K. (1999) Successful combination chemotherapy for a case of small cell carcinoma of the rectum with multiple liver metastasis. Jpn. J. Cancer Chemother., 26, 543-547.

Sato, H., Maruta, M., Maeda, K., Utsumi, T., Toyama, K., Okumura, Y., Masumori, K. \& Kuroda, M. (1998) Two cases of endocrine cell carcinoma of in the large bowel. $J$. Jpn. Surg. Assoc., 59, 1061-1067.

Sato, Y., Fujisawa, J., Saji, Y., Misawa, K., Yabuki, H., Kotani, H., Olii, Y., Minemoto, H., Kamada, T., Saito, H. \& Kanda, M. (1992) A case of small cell undifferentiated carcinoma (SCUC) of the rectum treated with etoposide, cis-platinum and radiotherapy. Jpn. J. Cancer Chemother., 19, 2245-2249.

Shimada, K., Ueno, S., Oshima, Y., Nakamura, H., Hiki, Y. \& Kakita, A. (1998) A case of endocrine cell carcinoma of the rectum. J. Jpn. Surg. Assoc., 59, 1346-1349.

Shinto, E., Mochizuki, H., Terahata, S., Furuya, Y., Uchida, T. \& Sakai, Yu. (1997) A case of cecal neuroendocrine carcinoma with foci of adenocarcinoma and squamous carcinoma. Jpn. J. Gastroenterol. Surg., 30, 2210-2214.

Shirouzu, K., Morodomi, T., Isomoto, H., Yamauchi, Y.,
Kakegawa, T. \& Morimatsu, M. (1985) Small-cell carcinoma of the rectum. Clinicopathologic study. Dis. Colon Rectum, 28, 434-439.

Shirouzu, K., Morodomi, T., Isomoto, H., Ono, S., Kakegawa, T., Yasuaki, F. \& Morimatsu, M. (1987) Long term survival case of small (oat) cell carcinoma of the rectum. Acta Pathol. Jpn., 37, 111-116.

Slade, M.S., Simmons, R.L., Yunis, E. \& Greenberg, L.J. (1975) Immunodepression after major surgery in normal patients. Surgery, 78, 363-372.

Tazaki, T., Nakai, S., Fujimoto, M., Santo, T., Miyamoto, K., Kawamura, H. \& Yasui, W. (2002) A case of endocrine cell carcinoma of the transverse colon. J. Jpn. Surg. Assoc., 63, 639-643.

Turrisi, A.T., III., Kim, K., Blum, R., Sause, W.T., Livingston, R.B., Komaki, R., Wagner, H., Aisner, S. \& Johnson, D.H. (1999) Twice-daily compared with once-daily thoracic radiotherapy in limited small-cell lung cancer treated concurrently with cisplatin and etoposide. N. Engl. J. Med., 30, 265-271.

Vilor, M., Tsutsumi, Y., Osamura, R.Y., Tokunaga, N., Soeda, J., Ohta, M., Nakazaki, H., Shibayama, Y. \& Ueno, F. (1995) Small cell neuroendocrine carcinoma of the rectum. Pathol. Int ., 45, 605-609.

Wang, B.S., Heacock, E.H., Wu, A.V. \& Mannick, J.A. (1980) Generation of suppressor cells in mice after surgical trauma. J. Clin. Invest., 66, 200-209.

Watanabe, I., Yamauchi, H., Iwamasa, K., Kohno, M., Takada, K. \& Sugita, A. (2002) Endocrine cell carcinoma (atypical carcinoid) of the ileocecal region adjacent to an adenocarcinoma. Jpn. J. Geriat., 39, 549-553.

Yamauchi, K., Miyata, T., Okada, N., Nitta, T., Kawai, H. \& Miyashita, T. (2004) A case of endocrine cell carcinoma of the rectum. J. Jpn. Surg. Assoc., 65, 751-755.

Yukawa, N., Akaike, M., Sugimasa, Y., Takemiya, S., Kameda, Y. \& Imada, T. (2002) 42-Month survival following chemotherapy for small-cell rectal carcinoma. Jpn. J. Gastroenterol. Surg., 35, 1443-1447. 